\title{
Alteration of cervical mucus by vanguard human spermatozoa
}

\author{
D. F. Katz*, B. T. Brofeldt*, J. W. Overstreet*† and F. W. Hanson* \\ Departments of *Obstetrics and Gynecology and of $\nmid$ Human Anatomy, School of Medicine, \\ University of California at Davis, Davis, California 95616, U.S.A.
}

\begin{abstract}
Summary. Movement characteristics of 'vanguard' and 'following' human spermatozoa within cervical mucus were measured using high-speed cinemicrography. The data were applied to a mathematical model of the hydrodynamics of sperm-mucus interaction, using the methods of analysis of covariance and stepwise multiple regression. Vanguard spermatozoa swam more rapidly and more efficiently than did following spermatozoa, although the flagellar beat frequencies and amplitudes of the spermatozoa in the two populations did not differ. This distinction in sperm-mucus hydrodynamics could be due to reduced flagellar thrust and/or increased mucous resistance experienced by the following spermatozoa.
\end{abstract}

\section{Introduction}

Sperm transport in the human female begins with rapid colonization of the cervical mucus by vigorously motile spermatozoa (Sobrero \& MacLeod, 1962). The vaginal environment is normally deleterious to sperm survival, and it appears that sperm numbers in the cervix have reached a maximum by 30-240 min post coitum (Tredway et al.,1975). The initial rapid entry of spermatozoa into the cervical mucus is probably aided by vaginal and uterine contractions (Overstreet \& Katz, 1977). The transit of spermatozoa from semen to mucus is also dependent on sperm flagellar activity and may be facilitated by the action of seminal enzymes on the semen-mucus interface (Overstreet, Coats, Katz \& Hanson, 1980).

Once spermatozoa have entered the cervix, their continued migration is the result of interaction between the swimming spermatozoa and microstructure of cervical mucus. The mucus is constructed of a network of fibrous macromolecules, with interstices which measure only a few micrometres (Katz \& Berger, 1980; Tam, Katz \& Berger, 1980). Since the sperm body is in close apposition to the mucous macromolecules, the two structures interact both hydrodynamically and mechanically. Only recently has the biological and clinical importance of these interactions become apparent. Observers of human sperm-cervical mucus interaction in vitro have stated that the "vanguard" spermatozoa which first enter mucus appear to encounter a very high resistance, and they have speculated that such spermatozoa require an "extra driving force" (Gaddum-Rosse, Blandau \& Lee, 1980). In contrast, those spermatozoa that follow the vanguard are said to encounter less resistance in the mucus, and presumably swim at a higher speed than do the vanguard spermatozoa.

If vanguard spermatozoa 'clear a path' for those following, then sustained migration of the following spermatozoa into and through the mucus would be facilitated. In contrast, if the vanguard have a locomotive advantage and the followers a disadvantage, the sperm population which first reaches the mucus would represent the majority of the spermatozoa subsequently 'stored' by the cervix. The mucus would then act to restrict sustained migration from the vagina, 
because the slower following spermatozoa would be more susceptible to elimination via continued mucous outflow. The experiments described in this paper were designed to answer whether there is a true distinction between swimming behaviour of vanguard and following spermatozoa in human cervical mucus.

\section{Materials and Methods}

\section{Experimental}

Semen samples (at least $40 \times 10^{6}$ spermatozoa $/ \mathrm{ml}$ and $50 \%$ motile cells) were obtained from 7 healthy, fertile men after at least 2 days of sexual abstenence. Specimens were collected by masturbation, and utilized for study within $1 \mathrm{~h}$ after reliquefaction. Seven samples of midcycle human cervical mucus were collected from healthy, fertile women by gentle suction into a catheter (Katz, Overstreet \& Hanson, 1980). Mucous samples were selected on the basis of clarity and spinnbarkeit and all were collected within $24 \mathrm{~h}$ of the nadir of the basal body temperature curve. The sperm-mucus interaction experiments were initiated within 10 min of mucous collection.

The movement characteristics of spermatozoa in cervical mucus were studied in capillary tubes of rectangular cross-section: $400 \mu \mathrm{m}$ deep, $4 \mathrm{~mm}$ wide, and $5 \mathrm{~cm}$ long (Vitro Dynamics, Rockaway, New Jersey, U.S.A.). Mucus was slowly drawn into a tube, the upstream end of which was then sealed. The tube was placed on a microscope slide, and a small amount of semen was injected into the open end, such that it gently contacted the mucus. The open end was then sealed, and the preparation was placed on the stage of a microscope, maintained at $37^{\circ} \mathrm{C}$ by a forced hot air curtain. Sperm movement was visualized by dry phase-contrast optics with a $\times 20$ objective lens. All observations and recordings were made $2 \mathrm{~cm}$ from the semen-mucus interface. The plane of focus was the midplane of the tube cross-section, as determined by the fine focussing vernier of the microscope. Two distinct groups of spermatozoa were studied: the 'vanguard' spermatozoa that first arrived at the $2 \mathrm{~cm}$ station; and the 'following' spermatozoa that arrived at this region approximately $10 \mathrm{~min}$ later, i.e. after numerous spermatozoa had already permeated the mucus. The spermatozoa from each of the 7 semen specimens were examined twice, once for vanguard spermatozoa and once as following spermatozoa.

Sperm movement was recorded using high-speed cinemicrography. A Redlake Locam camera was employed at a framing rate of 100 frames/sec. The film was Kodak $4 \mathrm{X}$ negative. For each preparation, 10-20 motile vanguard spermatozoa and a similar number of following spermatozoa were photographed. Processed cine films were analysed frame-by-frame to obtain the following set of movement characteristics for each spermatozoon: (1) straight line swimming speed, $\mathrm{V}(\mu \mathrm{m} / \mathrm{sec})$, the straight-line distance between the initial and final positions of the junction of the sperm head and midpiece, as measured over $0.5 \mathrm{sec}$ of elapsed real time or the interval between two successive flashes of the sperm head, whichever was shorter; (2) rolling frequency of the spermatozoon, $\sigma(\mathrm{Hz})$, obtained with respect to the time interval between two consecutive flashes of the sperm head, i.e. one half of a complete roll cycle; (3) flagellar beat frequency, $f$ $(\mathrm{Hz})$, the sum $\mathrm{f}_{a}+\sigma$, where $\mathrm{f}_{a}$ is the apparent beat frequency, as counted between the two flashes of the sperm head (Denehy, Herbison-Evans \& Denehy, 1975) and (4) beat amplitude, b ( $\mu \mathrm{m})$, measured from a tracing of the flagellum in its position of maximum amplitude during the analysis interval.

\section{Theoretical}

Statistical analysis of the data had two objectives. First, differences in individual movement characteristics of vanguard and following spermatozoa were studied using analysis of variance. A two-way layout was employed, the main effects being the experiment (random) and the distinction vanguard/follower (fixed). The second objective of the data analysis was to gain 
information on the mechanical properties of the mucus as experienced by the vanguard and the following spermatozoa. The swimming speed of a spermatozoon in mucus is the hydrodynamic consequence of the flagellar beat frequency and shape, the morphology and surface properties of the sperm body, and the biophysical properties of the mucus. If spermatozoa with equivalent beats, morphologies and surface properties swim at different speeds in mucus, the inequality of such speeds must result from differences in the properties of the mucus through which the spermatozoa are swimming. Thus, the spermatozoon can be used as a biophysical probe of the mucus structure within a localized region.

This concept was applied using the statistical technique of analysis of covariance. The model employed in the covariance analysis was derived from fundamental hydrodynamic theory. Accordingly, the generalized equation which relates sperm swimming speed in mucus to both flagellar activity and mucus properties (Katz \& Berger, 1980) is

$$
\mathrm{V}=\sum_{n=1}^{N} \mathrm{~F}_{n}\{\text { frequency }\} \cdot \mathrm{G}_{n}\{\text { shape }\} \cdot \mathrm{H}_{n}\{\text { mucus }\} \cdot \mathrm{J}_{n}\{\text { sperm }\}
$$

Here there is an unknown number, $\mathrm{N}$, of terms, and the $\mathrm{F}_{n}, \mathrm{G}_{n}$, and $\mathrm{J}_{n}$ are mathematical functions that depend respectively upon beat frequency, shape and the physical properties (morphology and surface) of the spermatozoa, while the $\mathrm{H}_{n}$ are functions that depend upon the physical properties of the mucus as experienced by the spermatozoon. The following simple version of equation (1) was employed in the present study (Katz \& Berger, 1980)

$$
\mathrm{V}=\mathrm{Cf}^{\alpha} \mathrm{b}^{\beta}
$$

where $C$ is a coefficient characterizing the properties of spermatozoa and mucus. Therefore, the model used in the analysis of covariance was

$$
\ln \left(\mathrm{V}_{i j k}\right)=\mathrm{A}_{i}+\mathrm{B}_{j}+(\mathrm{AB})_{i j}+\alpha\left[\ln \left(\mathrm{f}_{i j k}\right)-(\overline{\ln \mathrm{f}})\right]+\beta\left[\ln \left(\mathrm{b}_{i j k}\right)-(\overline{\ln \mathrm{b}})\right]+\varepsilon_{i j k}
$$

Here $i$ refers to experiment number; $j$ has the values 1 or 2 for vanguard or following spermatozoa, respectively; $k$ is the sperm reference number; $\mathrm{A}_{i}$ and $\mathrm{B}_{j}$ are the main effects, i.e. the experiment and distinction vanguard/follower; $(\mathrm{AB})_{i j}$ is the interaction term; $(\overline{\operatorname{lnf}})$ and $(\overline{\operatorname{lnb}})$ are averages over both main effects; $\alpha$ and $\beta$ are regression coefficients; and $\varepsilon_{i j k}$ is the residual term. In order to complement the multiple regression portion of the analysis of covariance, the data for vanguard and following spermatozoa were also pooled over experiments and analysed separately by stepwise multiple regression techniques. The purpose of these analyses was to obtain the best fit to equation (2) for each class of spermatozoa.

\section{Results}

The results indicate that vanguard spermatozoa swam significantly faster than the spermatozoa which followed, despite the fact that their beat frequencies and beat amplitudes did not differ qualitatively or quantitatively (Table 1). Variation among experiments was also significant for all three movement characteristics, a probable reflection of differences in the mechanical properties of the different mucous samples. These distinctions were confirmed on a per sperm basis by the analysis of covariance, in which the distinction between vanguard and following spermatozoa $(P<0.001)$, as well as the inter-experiment variation $(P<0.001)$ were significant. Interactions between experiment and the distinction vanguard/follower were not significant in the analyses of variance and covariance. That is, this distinction was not influenced by variation in experimental materials (e.g. the mucous sample). 
Table 1. Movement characteristics (mean \pm s.e.m.) of vanguard and following human spermatozoa in fresh ovulatory human cervical mucus at $37^{\circ} \mathrm{C}$

\begin{tabular}{cccc}
\hline Sperm population & $\begin{array}{c}\text { Swimming speed, } \\
\mathrm{V}(\mu \mathrm{m} / \mathrm{sec})\end{array}$ & $\begin{array}{c}\text { Beat frequency, } \\
\mathrm{f}(\mathrm{Hz})\end{array}$ & $\begin{array}{c}\text { Beat amplitude, } \\
\mathrm{b}(\mu \mathrm{m})\end{array}$ \\
\hline Vanguard & $55 \pm 4$ & $25 \pm 1$ & $3 \cdot 15 \pm 0 \cdot 18$ \\
Followers & $42 \pm 4$ & $24 \pm 1$ & $3 \cdot 21 \pm 0 \cdot 17$ \\
\hline Source of Variation & & Analysis of variance \\
Experiment (A) & $* * *$ & $* * *$ & $* * *$ \\
Vanguard/Follower (B) & $* * *$ & N.S. & N.S. \\
A $\times$ B & N.S. & N.S. & N.S. \\
\hline
\end{tabular}

Data are pooled from 7 experiments involving semen and mucus from different men and women. *** $P<0.001 ;$ N.S., not significantly different.

The stepwise multiple regression analyses for vanguard and following spermatozoa indicated that $\ln (\mathrm{f})$ and $\ln (\mathrm{b})$ correlated significantly with $\ln (\mathrm{V})(P<0.001$ in all cases $)$. The regression equations reduced to the following expressions.

$$
\begin{array}{ll}
V=7.61 f^{0.51} b^{0.27} & \text { vanguard } \\
V=3.08 f^{0.58} b^{0.65} & \text { follower }
\end{array}
$$

The exponents of $f$ in equations (4) and (5) do not differ significantly, but the coefficients $(7.61$, $3.08)$ and the exponents of $b$ are significantly different $(P<0.001)$ in both cases. Therefore, the hydrodynamic interaction between vanguard spermatozoa and the mucus is different from that of following spermatozoa.

\section{Discussion}

The results of these experiments suggest that vanguard spermatozoa swam more efficiently in cervical mucus than did the spermatozoa which followed, i.e. they were able to swim faster at a given flagellar beat frequency. This is almost certainly attributable to an alteration in the properties of the mucus rather than to a difference in the vigour of the 2 sperm populations. In a hydrodynamic sense the flagellar beat frequency is a direct and independent measure of sperm energy production while the swimming speed depends also on the beat shape and the properties of the mucus. In these experiments the sperm vigour, as reflected in the beat frequency, was similar in vanguard and following populations. The different mucous properties experienced by the spermatozoa are represented mathematically in the hydrodynamic model by differences in the coefficients 7.61 and 3.08 and the exponents of 0.27 and 0.65 of equations (4) and (5).

The microstructure of cervical mucus has been studied by a number of techniques including electron microscopy (Chretien, Cernigon, David \& Psychoyos, 1973; Daunter, Chantler \& Elstein, 1976), nuclear magnetic resonance (Odeblad \& Rudolfsson, 1973; Katz \& Singer, 1978), rheometry (Litt, Khan \& Wolf, 1976; Wolf, Sokoloski, Khan \& Litt, 1977), laser light scattering (Lee, Verdugo, Blandau \& Gaddum-Rosse, 1977), and flow permeation methods (Tam, Katz, Berger \& Sensabaugh, 1982). There is a consensus that sperm movement is strongly influenced by the macromolecular architecture of the mucin network, but there is no agreement on either the organization of that network or its orientation in vivo. In a capillary tube in vitro, orientated mucus promotes unidirectional migration of spermatozoa. On the basis of the present results, it appears that in such a system the passage of vanguard spermatozoa alters the mucus microstructure so as to impede the following spermatozoa. This distinction could have resulted from reduced thrust produced by the sperm flagellum and/or increased resistance to the entire body. For example, mechanical disruption of macromolecular entanglements and 
cross-links may have increased elasticity of local mucus with a concomitant reduction in flagellar thrust (Katz \& Berger, 1980). Alternatively, adherent forces between the surfaces of the spermatozoa and the mucous macromolecules could have increased.

The capillary tube does not, of course, duplicate the entire cervical canal. During midcycle the human cervix actively produces mucus. The mucous microstructure may be aligned during the outward flow of the mucus, and it is possible that sperm-induced disruption of the microstructure would be 'healed' by the same process. Therefore, we can at present only speculate as to the biological relevance of those in-vitro phenomena. With regard to experimental or clinical studies in vitro, the implications of these findings are much clearer. The classical capillary tube penetration test measures the distance traversed by the forward most vanguard spermatozoa (Kremer, 1965). The results of such a test probably indicate the maximum capability of the spermatozoa in that particular mucous sample. More recent methods for assessing sperm-mucus interaction have focussed on the penetration rate and swimming behaviour of the entire sperm population (i.e. vanguard and following spermatozoa) (Katz et al., 1980). Clearly the results of the two tests cannot be directly compared because they measure different functions of the sperm population.

This work was supported by NIH grant HD12971 (D.F.K.) and research career development award HD00224 (J.W.O.).

\section{References}

Chretien, F.C., Cernigon, C., David, G. \& Psychoyos, A. (1973) The ultrastructure of human cervical mucus under scanning electron microscopy. Fert. Steril. 24, 746-751.

Daunter, B., Chantler, E. \& Elstein, M. (1976) Scanning electron microscopy of cervical mucus. Normal menstrual cycle and pregnancy. Br.J. Obstet. Gynec. 83, 738-746.

Denehy, M.A., Herbison-Evans, D. \& Denehy, B.V. (1975) Rotational and oscillatory components of the tailwave in ram spermatozoa. Biol. Reprod. 13, 289-297.

Gaddum-Rosse, P., Blandau, R.J. \& Lee, W.I. (1980) Sperm penetration into cervical mucus in vitro. $I$. Comparative studies. Fert. Steril. 33, 636-643.

Katz, D.F. \& Berger, S.A. (1980) Flagellar propulsion of human sperm in cervical mucus. Biorheology 17, 169-175.

Katz, D.F. \& Singer, J. R. (1978) Water mobility in bovine cervical mucus. Biol. Reprod. 17, 843-849.

Katz, D.F., Overstreet, J.W. \& Hanson, F.W. (1980) A new quantitative test for sperm penetration into cervical mucus. Fert. Steril. 33, 179-186.

Kremer, J. (1965) A simple sperm penetration test. Int. J. Fert. 10, 209-215.

Lee, W.I., Verdugo, P., Blandau, R.J. \& Gaddum-Rosse, P. (1977) Molecular arrangement of cervical mucus: a re-evaluation based on laser light-scattering spectroscopy. Gynecol. Invest. 8, 254-266.

Litt, M., Khan, M.A. \& Wolf, D.P. (1976) Mucus rheology: relation to structure and function. Biorheology 13, 37-48.
Odeblad, E. \& Rudolfsson, C. (1973) Types of cervical secretions: biophysical characteristics. In The Biology of the Cervix, pp. 267-284. Eds R. J. Blandau \& K. Moghissi. University of Chicago Press.

Overstreet, J.W. \& Katz, D.F. (1977) Sperm transport and selection in the female genital tract. In Mammalian Development, pp. 31-65. Ed. M. H. Johnson. Elsevier/North Holland, Amsterdam.

Overstreet, J.W., Coats, C., Katz, D.F. \& Hanson, F.W. (1980) The importance of seminal plasma for human sperm penetration of cervical mucus. Fert. Steril. 34, 569-572.

Sobrero, A.J. \& MacLeod, J. (1962) The immediate post-coital test. Fert. Steril. 13, 184-189.

Tam, P.Y., Katz, D.F. \& Berger, S.A. (1980) Nonlinear viscoelastic properties of cervical mucus. Biorheology 17, 465-478.

Tam, P.Y., Katz, D.F., Berger, S.A. \& Sensabaugh, G.F. (1982) Flow permeation analysis of bovine cervical mucus. Biophys. J. (In press).

Tredway, D.R., Fordney Settlage, D.S., Nakamura, R.M., Motoshima, M., Umezaki, C.U. \& Mishell, D.R. (1975) Significance of timing for the post-coital evaluation of cervical mucus. Am. J. Obstet. Gynec. 121, 387-393.

Wolf, D.P., Sokoloski, J., Khan, M.A. \& Litt, M. (1977) Human cervical mucus. III. Isolation and characterization of rheologically active mucin. Fert. Steril. 28, 53-58.

Received 6 July 1981 